\title{
D'TAMU (Desa Wisata Jamu): Hilirisasi Jamu Saintifik Diabetes Melitus
}

\author{
Muhammad Fadhol Romdhoni ${ }^{1}$, Dewi Karita ${ }^{2}$, Ira Citra Ningrom ${ }^{3}$ \\ Universitas Muhammadiyah Purwokerto, Jl. KH. Ahmad Dahlan, Dusun III, Dukuhwaluh, Kec. \\ Kembaran, Kabupaten Banyumas, Jawa Tengah 53182 \\ Email: fadhol.romdhoni@gmail.com ${ }^{1}$
}

\begin{abstract}
ABSTRAK
Pengabdian kepada masyarakat ini merupakan bagian dari program jangka panjang terkait penanggulangan penyakit tidak menular/Non Communicable Disease (NCD) secara mandiri oleh masyarakat, yang bertujuan untuk menggulangi masalah kesehatan khususnya penyakit degeneratif yakni Diabetes Melitus Tipe-2 (DMT2) di wilayah kerja Pimpinan Ranting Muhammadiyah (PRM) Desa Bantarwuni, kecamatan Kembaran, kabupaten Banyumas, Jawa Tengah yang memiliki angka kejadian sekitar 1.233 kasus. Penyakit tersebut sangat mengganggu kualitas hidup manusia sehingga akan mempengaruhi roda perekonomian masyarakat karena jika telah terkena penyakit tersebut maka seseorang tidak akan dapat bekerja secara optimal. Penanganan DMT2, selain dengan obat medis, dapat diberikan jamu saintifik. Pemahaman masyarakat penyiapan jamu saintifik secara benar merupakan hal yang penting disamping pemahaman tentang khasiat dan kandungan dari ramuan jamu itu sendiri. Metode pengabdian yang digunakan adalah dengan cara memperlihatkan secara langsung dan memberikan penjelasan tentang ramuan jamu saintifik untuk gangguan DMT2 kepada masyarakat yang hadir. Selanjutnya dilakukan simulasi penyiapan jamu saintifik yang disaksikan secara langsung oleh peserta dan selanjutnya peserta diminta untuk melakukannya sendiri dengan supervise dari penyaji. Setelah pengabdian ini, masyarakat menjadi faham tentang ramuan jamu saintifik untuk gangguan DMT2 dan mereka dapat melakukan penyiapan jamu saintifik dengan baik sesuai panduan.
\end{abstract}

Kata kunci: Desa Wisata Jamu, Jamu Saintifik, Diabetes Melitus

\section{ABSTRACT}

This engagement is part of a long-term program related to the prevention of non-communicable diseases (NCD) independently by the community, which aims to tackle health problems, especially degenerative diseases, namely Diabetes Mellitus Type-2 (T2DM) in the working area of Pimpinan Ranting Muhammadiyah (PRM) of Bantarwuni, Kembaran, Banyumas, Central Java which has an incidence of around 1,233 cases. Handling of T2DM, apart from medical drugs, can be given scientific herbal medicine. Therefore, public understanding of the correct preparation of scientific herbal medicine is essential in understanding the properties and contents of the herbal concoctions themselves. Therefore, the service method used is by showing directly and explaining scientific herbal concoctions for T2DM disorders to the people present. Furthermore, a simulation of the preparation of scientific herbal medicine was carried out, which was witnessed directly by the participants. Then the participants were asked to do it themselves with supervision from the presenter. After this service, the community became aware of scientific herbal concoctions for T2DM disorders, and they were able to prepare scientific herbs properly according to the guidelines.

Keywords: Herb Tourism Village, Scientific Herb Medicine, Diabetes Mellitus 


\section{PENDAHULUAN}

Diabetes Melitus tipe-2 (DMT2) merupakan jenis diabetes yang memiliki proporsi paling banyak dari total kasus diabetes yakni sebesar 90-95\% dari keseluruhan kasus (Bekki, Inaba, Uchiyama, \& Kunugita, 2017; Forouhi \& Wareham, 2014; Razzak, Harbi, Shelpai, \& Qawas, 2017; WHO, 2016). Angka kejadian DMT2 di Indonesia menurut Riset Kesehatan Dasar, terjadi peningkatan 1,1\% di tahun 2007 meningkat menjadi 2,1\% di tahun 2013 dari keseluruhan penduduk sebanyak 250 juta jiwa (Kementerian Kesehatan RI, 2018; Riskesdas, 2018). Pengabdian kepada masyarakat ini merupakan bagian dari program jangka panjang terkait penanggulangan penyakit tidak menular/Non Communicable Disease (NCD) secara mandiri oleh masyarakat, yang bertujuan untuk menggulangi masalah kesehatan khususnya penyakit degeneratif yakni Diabetes Melitus Tipe-2 (DMT2), dimana penyakit tersebut sangat mengganggu kualitas hidup manusia sehingga akan mempengaruhi roda perekonomian masyarakat karena jika telah terkena penyakit tersebut maka seseorang tidak akan dapat bekerja secara optimal, di wilayah Pimpinan Ranting Muhammadiyah (PRM) Desa Bantarwuni, kecamatan Kembaran, kabupaten Banyumas, Jawa Tengah dengan angka kejadian sekitar 1.233 kasus (Widianto, Romdhoni, Karita, \& Purbowati, 2019). Pimpinan Ranting Muhammadiyah Bantarwuni terletak di Desa Bantarwuni yang merupakan salah satu desa di wilayah administratif kecamatan Kembaran kabupaten Banyumas yang terdiri dari 27 RW dan 108 RT dengan jumlah penduduk sekitar 4000-an jiwa. Distribusi penduduk yang cukup merata antara usia muda maupun tua tentu memunculkan masalah yang berbeda-beda (DISPERMADESDUKCAPIL, 2020).

Penanggulangan penyakit tersebut selama ini hanya sekedar memberikan tatalaksana secara farmakologi. Padahal, menurut panduan pelatalaksanaan penyakit degeneratif menurut berbagai literature dan WHO yang pertama kali adalah pengelolaan gaya hidup / life style. Oleh karena itu, dalam mengatasi penyakit tersebut perlu kerjasama yang baik antara penderita, keluarga, tenaga medis, dan masyarakat, selanjutnya diupayakan dengan pemberian ramuan jamu saintifik (Punthakee, Goldenberg, \& Katz, 2018; Szkudelski, 2001). Ramuan saintifik untuk gangguan diabetes melitus terdiri dari daun salam, herba sambiloto, kulit kayu manis, dan rimpang temulawak (Tim B2P2TOOT, 2019).

\section{METODE}

Metode yang digunakan yaitu secara luring dengan cara datang ke Balai Desa Bantarwuni kemudian mengundang warga yang masuk dalam kriteria inklusi, yaitu yang 
memilik riwayat DMT2, untuk dilakukan pemeriksaan indikator DMT2 berupa gula darah sewaktu dan memberikan panci dari tanah liat. Proses pelaksanaan pengabdian dengan memperhatikan protokol Kesehatan COVID-19 diantaranya menggunakan Alat Pelindung Diri (APD), masker bedah, face shield, mencuci tangan, dan menjaga jarak.

Pelaksanaan pengabdian ini menggunakan gabungan metode, dengan tujuan memberikan pemahaman terhadap masyarakat tentang kandungan dan khasiat dari jamu saintifik diabetes melitus serta cara menyiapkan jamu saintifik dengan benar. Metode ceramah dipilih untuk memberikan pemahaman tentang jamu, kemudian dilanjutkan dengan simulasi langsung tentang perebusan jamu di hadapan peserta penyuluhan. Untuk memastikan bahwa materi penyuluhan telah dimengerti dengan baik oleh peserta maka peserta penyuluhan diminta untuk melakukan penyiapan jamu saintifik dengan supervise dari tim penyaji/pemateri.

\section{HASIL, PEMBAHASAN, DAN DAMPAK}

Pelaksanaan kegiatan dipusatkan di pendopo balai desa Bantarwuni, Kembaran, Banyumas yang merupakan tempat terbuka sehingga dirasa merupakan tempat yang tepat untuk melaksanakan kegiatan di masa pandemic COVID-19. Protokol Kesehatan COVID19 diantaranya menggunakan hazmat, masker bedah, handscoon, face shield, mencuci tangan, dan menjaga jarak. Kegiatan ini dihadiri oleh 11 undangan dengan distribusi sebagai berikut:

Tabel 1. Distribusi peserta pengabdian masyarakat

\begin{tabular}{cc}
\hline Jenis Kelamin & Jumlah $(\%)$ \\
\hline Laki - laki & 46 \\
\hline Perempuan & 54 \\
\hline
\end{tabular}

Seluruh peserta merupakan orang yang memiliki riwayat menderita diabetes melitus tipe-2 sebelumnya. Setelah dilakukan pemeriksaan gula darah sewaktu, didapatkan kadar gula darah peserta seperti yang tersaji dalam tabel 2.

Tabel 2. Kadar gula darah sewaktu dari peserta

\begin{tabular}{lc}
\hline \multicolumn{1}{c}{ Deskripsi data } & Kadar Gula Darah Sewaktu (mg/dL) \\
\hline Minimum & 148 \\
\hline Median & 214 \\
\hline Maksimum & 407 \\
\hline Keterangan: data tidak ditampilkan rerata karena distribusinya tidak normal $(\mathrm{p}<0,05)$
\end{tabular}


Pelaksanaan pengabdian dilaksanakan secara sederhana namun tetap khidmat dengan beberapa rangkaian acara. Diawali dengan seremoni pembukaan yang diisi pemaparan singkat tentang tujuan pengabdian masyarakat pleh penyaji, kemudian sambutan oleh Ketua PRM Bantarwuni dan dibuka oleh Bapak Kades Bantarwuni (seperti yang tampak pada gambar 1). Agenda selanjutnya adalah simulasi penyiapan jamu saintifik oleh penyaji dan selanjutnya meminta peserta untuk mencoba menyiapkan jamu saintifik dengan supervise dari penyaji (seperti yang tampak pada gambar 2 dan gambar 3). Bahan jamu berasal dari Balai Besar Penelitian dan Pengembangan Tanaman Obat dan Obat Tradisional (B2P2TOOT) Tawangmangu, Jawa Tengah.
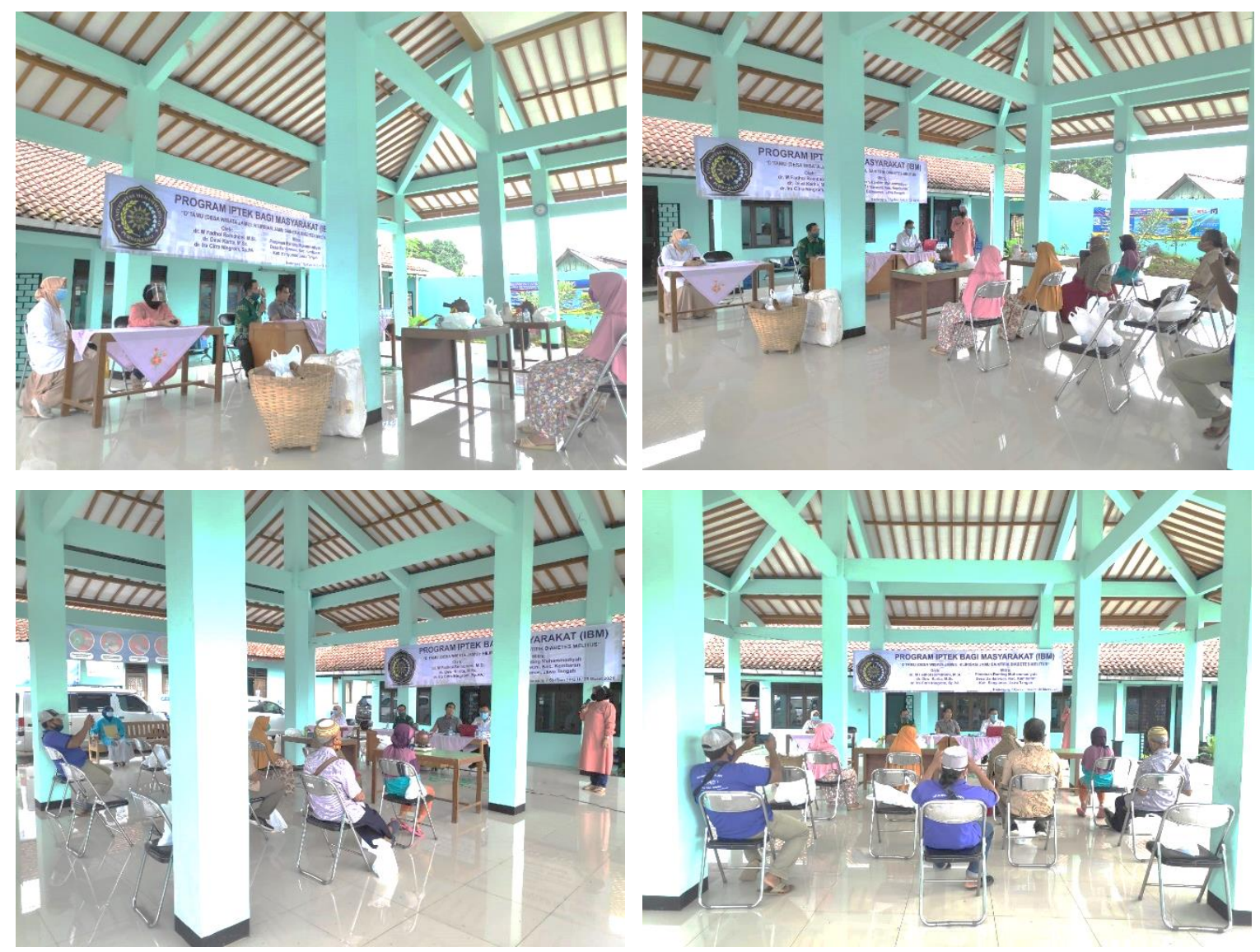

Gambar 1. Seremoni Pembukaan Acara Pengabdian pada Masyarakat yang Diawali dengan Pemaparan Penyaji, Dilanjutkan dengan Sambutan oleh Ketua PCM Bantarwuni, dan Dibuka oleh Kades Bantarwuni 

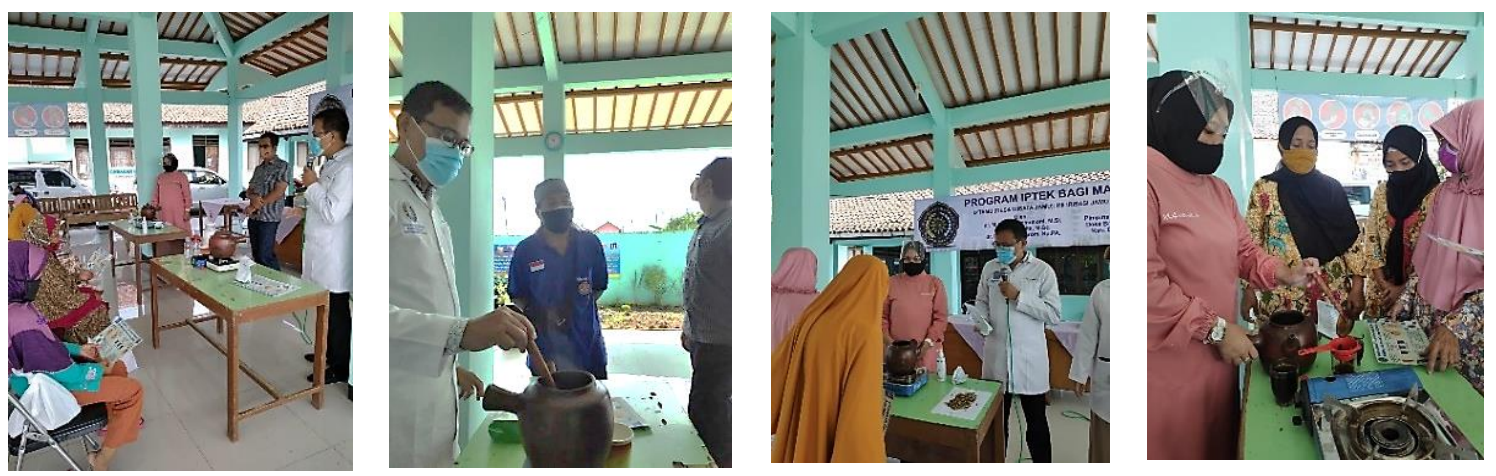

Gambar 2. Simulasi Penyiapan Jamu Saintifik oleh Penyaji
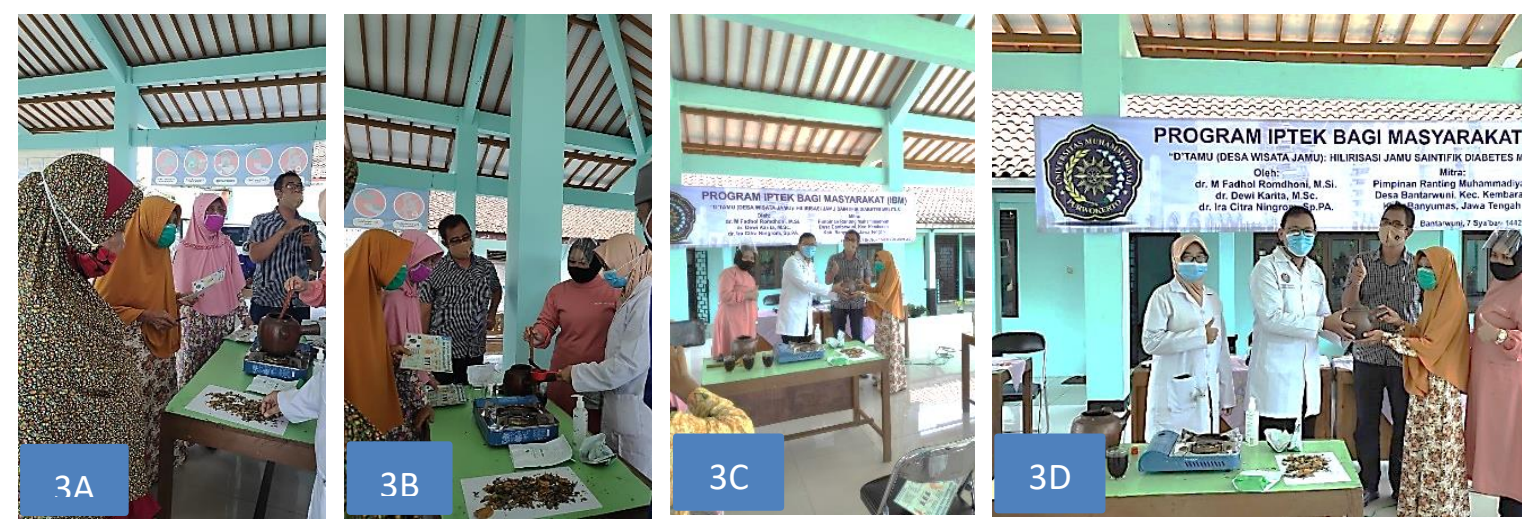

Gambar 3A, 3B Peserta Mencoba Sebagian Prosedur Penyiapan Jamu Saintifik dan Gambar 4C, 3D Pemberian Cinderamata Berupa Panci Tanah Liat

Selain pemberian materi serta dilakukan simulasi, peserta pengabdian juga diberikan leaflet/poster yang berisi informasi tentang proses menyediakan jamu saintifik serta kandungan dari ramuan jamu saintifik untuk diabetes melitus.

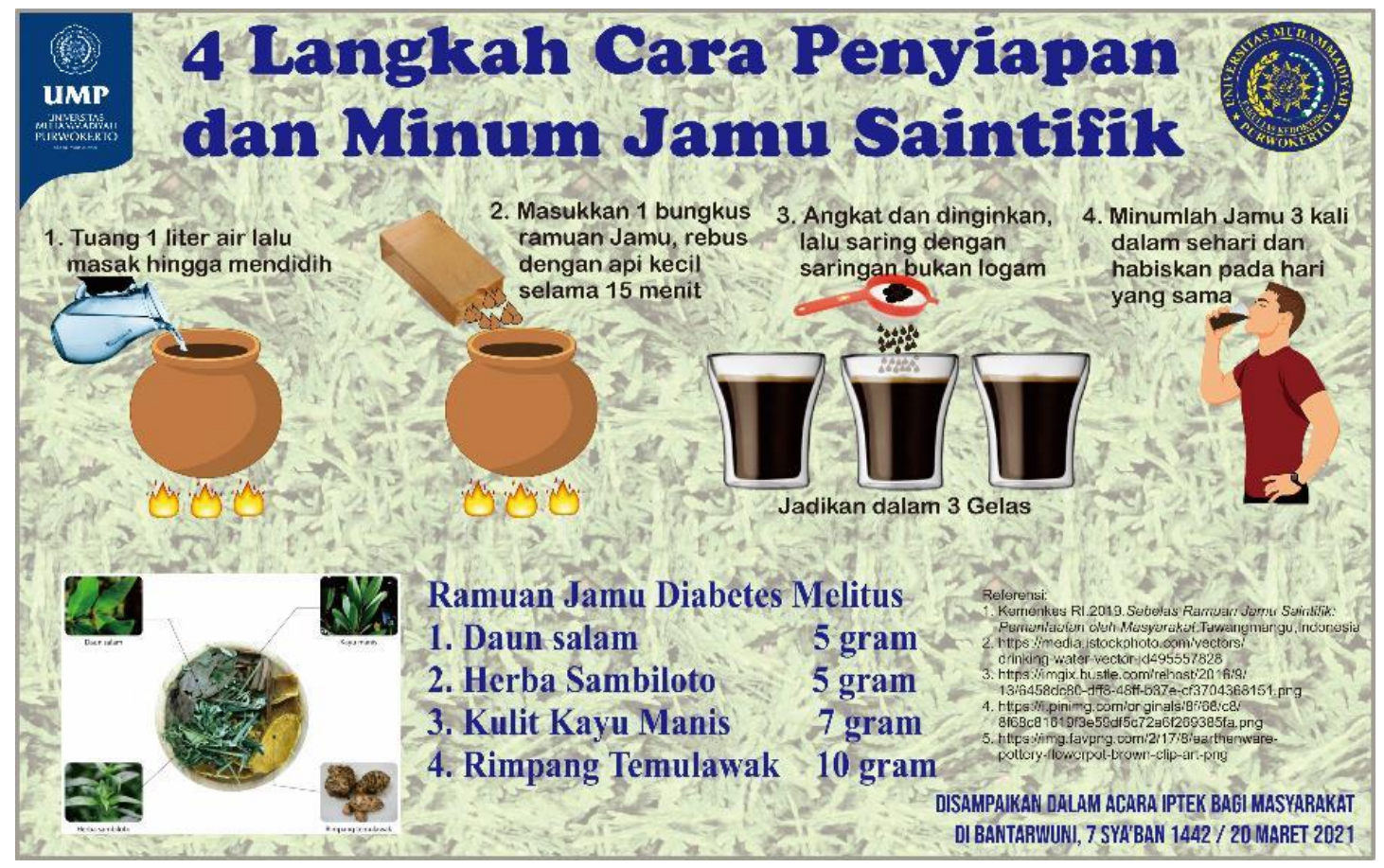

Gambar 5. Leaflet/poster cara penyiapan jamu dan informasi kandungan ramuan jamu DM 
Penyaji menanyakan secara lisan tentang pemahaman peserta tentang cara penyiapan jamu ini dan seluruhnya menyatakan memahaminya. Ketika peserta melakukan simulasi penyiapan jamu saintifik, tampak bahwa peserta dapat melaksanakan urutan dengan baik. Peserta juga memperoleh pemahaman tentang manfaat dari ramuan jamu serta takarannya.

\section{SIMPULAN}

Setelah dilaksanakan pengabdian, seluruh peserta memahami tentang ramuan jamu seperti istilah herba dan rimpang, takaran untuk membuat ramuan, dan manfaat dari ramuan jamu khususnya untuk gangguan diabetes melitus. Peserta juga dapat menyiapkan jamu saintifik sesuai dengan tata cara yang diberikan.

\section{UCAPAN TERIMAKASIH}

Terima kasih kami sampaikan kepada Pimpinan Ranting Muhammadiyah Bantarwuni, Kepala Desa serta Warga desa Bantarwuni, Kecamatan Kembaran, Kabupaten Banyumas atas kerjasamanya yang baik sehingga agenda pengabdian ini berjalan dengan baik. Tak lupa, kami juga mengucapkan terima kasih kepada mahasiswa FK-UMP yaitu Religia Azhar, Sri Mega Mutmainah, dan Yusuf Indra yang telah membantu pelaksanaan pengabdian masyarakat ini. Selanjutnya, kami juga mengucapkan terima kasih kepada LPPM UMP yang telah memberikan alokasi anggaran dan kepada Balai Besar Penelitian dan Pengembangan Tanaman Obat dan Obat Tradisional (B2P2TOOT) Tawangmangu, Jawa Tengah sebagai penyuplai jamu saintifik.

\section{DAFTAR PUSTAKA}

Bekki, K., Inaba, Y., Uchiyama, S., \& Kunugita, N. (2017). Comparison of chemicals in mainstream smoke in heat-not-burn tobacco and combustion cigarettes. Journal of UOEH, 39(3), 201-207. doi: 10.7888/juoeh.39.201

DISPERMADESDUKCAPIL, P. J. (2020). Bantarwuni, Kembaran, Banyumas. Retrieved March 21, 2021, from https://sidesa.jatengprov.go.id/desa/33.02.20.2014

Forouhi, N. G., \& Wareham, N. J. (2014). Epidemiology of diabetes. Medicine, 42(12), 698702.

Kementerian Kesehatan RI. (2018). Pusat Data dan Informasi Tuberkulosis. InfoDATIN. ISSN: 2442-7659.

Punthakee, Z., Goldenberg, R., \& Katz, P. (2018). Definition, Classification and Diagnosis of Diabetes, Prediabetes and Metabolic Syndrome. Canadian Journal of Diabetes, 42 , S10-S15. doi: 10.1016/j.jcjd.2017.10.003 
Razzak, H. A., Harbi, A., Shelpai, W., \& Qawas, A. (2017). Epidemiology of Diabetes Mellitus in the United Arab Emirates. Current Diabetes Reviews.

Riskesdas, K. (2018). Hasil Utama Riset Kesehata Dasar (RISKESDAS). Journal of Physics A: Mathematical and Theoretical, 44(8), 1-200. doi: 10.1088/1751-8113/44/8/085201

Szkudelski, T. (2001). <Mechanism of Streptozotocin.Pdf>. doi: 10.1111/j.1464$\underline{5491.2005 .01499 . x}$

Tim B2P2TOOT. (2019). Sebelas Ramuan Jamu Saintifik. Journal of Chemical Information and Modeling, 53(9), 1689-1699.

WHO. (2016). Diabetes Country Profile Indonesia. Who, 48(6), 18882A-18882B. doi: 10.1111/j.1467-825X.2011.03931.X

Widianto, A. A., Romdhoni, M. F., Karita, D., \& Purbowati, M. R. (2019). Hubungan Pola Makan Dan Gaya Hidup Dengan Angka Kejadian Hipertensi Pralansia Dan Lansia Di Wilayah Kerja Puskesmas I Kembaran. MAGNA MEDICA: Berkala Ilmiah Kedokteran Dan Kesehatan, 1(5), 58. doi: 10.26714/magnamed.1.5.2018.58-67 